For submission to Colloids and Surfaces A: Physicochemical and Engineering Aspects

\title{
Adsorption of silica colloids onto like-charged silica surfaces of different roughness
}

\author{
R. Dylla-Spears*, L. Wong, N. Shen, W. Steele, J. Menapace, P. Miller, M. Feit, and T. \\ Suratwala \\ Lawrence Livermore National Laboratory, P.O. Box 808, Livermore, CA 94551, USA \\ *dyllaspears1@llnl.gov
}

\begin{abstract}
Particle adsorption was explored in a model optical polishing system, consisting of silica colloids and like-charged silica surfaces. The adsorption was monitored in situ under various suspension conditions, in the absence of surfactants or organic modifiers, using a quartz crystal microbalance with dissipation monitoring (QCM-D). Changes in surface coverage with particle concentration, particle size, $\mathrm{pH}$, ionic strength and ionic composition were quantified by QCM-D and further characterized ex situ by atomic force microscopy (AFM). A Monte Carlo model was used to describe the kinetics of particle deposition and provide insights on scaling with particle concentration. Transitions from near-zero adsorption to measurable adsorption were compared with equilibrium predictions made using the Deraguin-Verwey-Landau-Overbeek (DLVO) theory. In addition, the impact of silica surface roughness on the propensity for particle adsorption was studied on various spatial scale lengths by intentionally roughening the QCM sensor surface using polishing methods. It was found that a change in silica surface roughness at the AFM scale from 1.3 $\mathrm{nm}$ root-mean-square ( $\mathrm{rms}$ ) to $2.7 \mathrm{~nm} \mathrm{rms}$ resulted in an increase in silica particle adsorption of 3-fold for 50-nm diameter particles and 1.3-fold for 100-nm diameter particles—far exceeding adsorption observed by altering suspension conditions alone,
\end{abstract}


potentially because roughness at the proper scale reduces the total separation distance between particle and surface.

\section{Graphical Abstract}

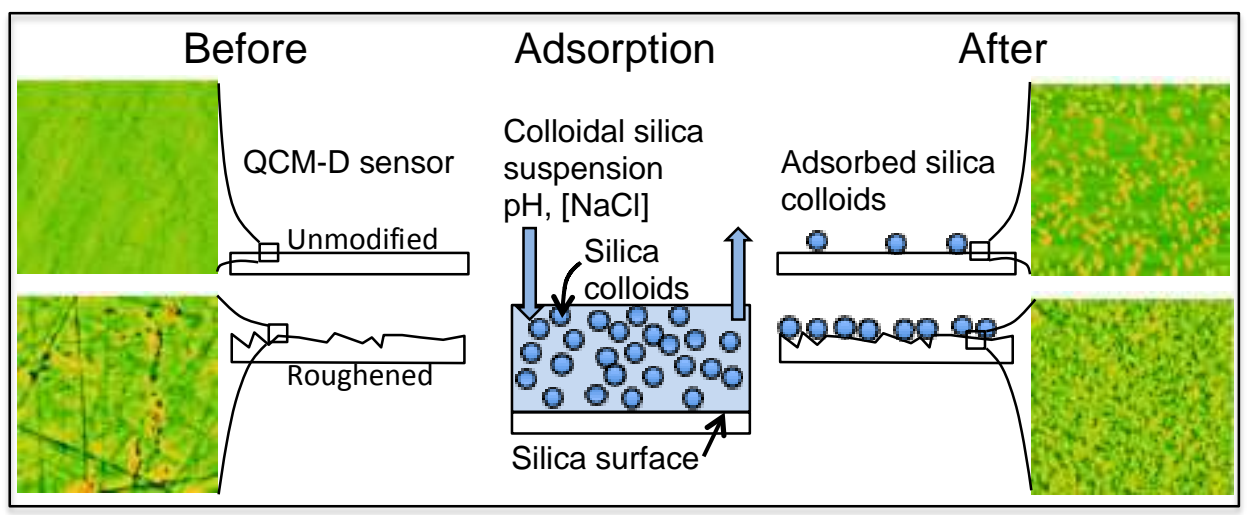

\section{Keywords}

Colloidal silica; adsorption; QCM; DLVO theory; surface roughness; polishing

\section{Introduction}

Processes such as optical polishing and chemical-mechanical planarization (CMP) involve the use of slurries of abrasive particles, often ceria or silica, to effect the physical and chemical removal of material from inorganic substrates such as silica glass or silicon with the goal of achieving a desired figure or surface finish. Material is removed from the substrate (as ions, molecules, and/or particles) and becomes entrained in the slurry, substantially changing the slurry composition proximate to the surface being polished. Both the abrasive particles and the removal products have the potential to adsorb onto surfaces with which they come into contact. Adsorption of slurry particles and/or re-deposition of removal products onto the part being 
polished (i.e. the workpiece) can affect both the polishing outcome and the finished surface quality. ${ }^{1,2}$ Further, some contaminants can also be difficult to remove in subsequent processing steps. ${ }^{3}$ In addition, surface interactions between polishing surface, polishing pad, and slurry particles have recently been shown to influence roughness at the $10 \mu \mathrm{m}-1 \mathrm{~mm}$ length scale. ${ }^{4}$

The propensity for metal oxide particle deposition onto a metal oxide surface depends on a number of factors, including the chemistry of both the adsorbate and the surface, as well as $\mathrm{pH}$, ionic strength, and adsorbate size. In addition, it has been suggested that surface topography, which evolves throughout and is an outcome of the polishing process, plays a role in species adsorption. ${ }^{5}$ An improved understanding of the roles of various species on adsorption to the workpiece or polishing pad as polishing progresses, as well as the impact of the surface texture, could provide insights and strategies to improve polishing slurry formulations. For example, tailoring chemical conditions to prevent undesired adsorption may lead to improvements in midscale roughness and/or reduce the propensity for downstream process surface contamination.

A quartz crystal microbalance with dissipation monitoring capability (QCM-D) is a tool frequently used to characterize both the degree and nature of the adsorption of species on a substrate under different conditions. Many such studies have centered on the adsorption of cells, biomolecules, proteins, or polymers. ${ }^{6,7}$ Recently, a number of studies have utilized the QCM-D technique to study the adsorption of nanoparticles onto functionalized surfaces in the context of assessing their environmental fates. ${ }^{9}$ A small fraction have reported using QCM-D to investigate the adsorption of metal oxide nanoparticles onto surfaces in pairs that may be of particular interest in polishing science because of their use in optics or in polishing compounds: e.g. cerium 
oxide deposition on silica and alumina ${ }^{10}$, silica deposition on alumina ${ }^{11}$, and titania deposition on silica $^{12}$. Such studies have primarily focused on the adsorption of particles onto dissimilar surfaces, typically under electrostatically attractive conditions where organic matter is often introduced to affect deposition. In addition, the particle sizes are often smaller than those typically used in optical polishing or CMP. Nonetheless, these efforts suggest that QCM-D may be useful for investigating slurry interaction with polishing-relevant surfaces.

In this work, we investigate the conditions necessary to initiate adsorption in a simple model metal oxide polishing system involving monodispersed silica colloids adsorbing onto likecharged silica surfaces, where deposition onto the surface is generally electrostatically unfavorable. No organic additives are used in the present studies. Changes in adsorption with particle concentration, particle size, $\mathrm{pH}$, ionic strength and ionic composition are quantified by QCM-D and then further characterized by examining the sensor surface ex situ using atomic force microscopy (AFM). The results of these experiments are compared directly with predictions from Derjaguin-Verwey-Landau-Overbeek (DLVO) theory. In addition, the impact of substrate roughness (introduced by intentionally roughening the silica QCM sensor surfaces) on the propensity for adsorption are explored over several roughness length scales and with different particle sizes.

\section{Materials and Methods}

\subsection{Suspension Preparation}

Under ambient conditions, suspensions of monodispersed colloidal silica particles (Polysciences, Inc.) of different sizes were prepared at various salt/ionic $\left(\mathrm{NaCl}\right.$ and $\left.\mathrm{K}_{3} \mathrm{PO}_{4}\right)$ concentrations and 
particle concentrations as well as different $\mathrm{pHs}$. Suspensions were prepared by adding constituents in the following order: 1) silica particles, 2) ultra-pure/deionized (DI) (17-18 M $\Omega$ ) water, and 3) $1 \mathrm{M} \mathrm{NaCl}$ or $1 \mathrm{M} \mathrm{K}_{3} \mathrm{PO}_{4}$. To minimize any changes in the temporal behavior of the suspension, all solutions were prepared within a few hours of the QCM-D measurement. Any $\mathrm{pH}$ adjustments were made using $\mathrm{HCl}$ and $\mathrm{KOH}$. The average size of the silica particles in each suspension was characterized by dynamic light scattering (DLS) with a Coulter N4 Plus Particle Sizer (Beckman Coulter, Florida).

\subsection{QCM-D Sensor-surface roughening}

Particle adsorption was evaluated on unmodified silica-coated sensor crystals (Q-Sense QSX 303, Biolin Scientific, Sweden) and on silica sensors that had been intentionally roughened. Where indicated, silica-coated sensor crystals were roughened via one of two methods: (1) manual loose-abrasive grinding and (2) ceria polishing in the presence of rogue particles. ${ }^{13}$

Manual loose-abrasive grinding consisted of masking the electrode side of the sensor with cleanroom tape (CR 100 PC, Micronova Manufacturing, Inc.), flooding the surface of a fused silica plate with a dilute (30 w/w) Microgrit 30T alumina slurry (Universal Photonics, Hicksville NY), inverting the coated side of the sensor onto the plate and then subjecting the sensor to 3 or 4 "figure-8" passes under nominal finger pressure. The 30T-abraded sensors were then rinsed and sonicated (E/MC, a division of RAI Research, ultrasonic cleaner, model 250) with DI water for 5 minutes, further sonicated in 2 w/w Sodium Dodecyl Sulfate (SDS) for 2 minutes, and then finally rinsed with another $100 \mathrm{ml}$ DI water. The sensors were dried using a flow of compressed, filtered air. 
Ceria polishing required that the sensors first be blocked to ensure relative flatness prior to polishing. Blocking consisted of 1) placing a 2-mm thick, 4" diameter fused silica plate on the countertop, 2) masking the electrode side of three individual sensors with cleanroom tape, 3) placing each sensor with the taped side up onto the 2-mm thick fused silica plate in a triangular formation $\left(120^{\circ}\right.$ apart $\left.), 4\right)$ dabbing a drop of nail polish in the center of each taped surface, 5) placing a second, 2-mm thick, 4" diameter fused silica plate on top of the nail polish droplets, 6) adding a 1-cm thick, 4" diameter fused silica plate on top of the stack, 7) adding a 50-gram weight to the stack, and 8) allowing the plates to equilibrate and cure overnight. Once cured, the blocked sensors were polished using the following parameters: 1) orbital polisher in continuous polishing (CP) mode, 2) Stabilized Hastilite PO slurry adjusted to $\mathrm{pH} 9$ and Baume 5, 3) diamond-conditioned MHN polyurethane pad (Eminess Technologies, Scottsdate, AZ) with 1cm x-y groove pattern, 1-mm wide and deep grooves, 4) 200-g load over 4X sensor area, 5) lap and optic rotation speed of $20 \mathrm{rpm}, 6) 1$ " stroke, 7) foam taped to the 4" optic (block) and 8) 7minute polishing time. ${ }^{14}$ After polishing, the blocked sensors were cleaned with 1 wt $\%$ Micro90 (Cole-Palmer, Vernon Hills, IL) surfactant solution in water using $70 \mathrm{kHz}$ ultrasonic frequency. The sensors were de-blocked by soaking in acetone for 4 hours minimum, mechanically rubbed with additional acetone to remove any residual adhesive from the cleanroom tape, cleaned and sonicated in $1 \mathrm{wt} \%$ Micro-90 detergent, rinsed with copious amounts of DI water, and dried using a flow of compressed, filtered air. 
For both manually-ground and polished sensors, micro-roughness was measured using white light interferometry (WYKO NT3300), and sensors were viewed with optical microscopy (KEYENCE VHX-2000) to ensure process consistency.

\subsection{QCM-D Measurements}

To help ensure sensor surface consistency among experiments, a new silica-coated QCM-D sensor was used for each experiment. All silica-coated sensor crystals were subjected to a standardized cleaning protocol prior to measurement. The sensors were first placed in a UVOzone cleaner (Helios-500 model, UVOTECH Systems, Inc.), approximately $1 \mathrm{~cm}$ from the lamp, for 10 minutes. The sensors were subsequently immersed and sonicated in $2 \% \mathrm{w} / \mathrm{w}$ SDS for at least 1 minute and then immediately rinsed with approximately $100 \mathrm{ml}$ of DI water. Surfaces were not allowed to dry prior to the water rinse. The sensors were then dried using a flow of compressed, filtered air and subjected to a final UV-Ozone treatment for another 10 minutes.

Prior to each QCM measurement on the Q-Sense E1 (Biolin Scientific, Sweden), a "dummy” or designated silica-coated cleaning sensor was used to clean the Q-Sense standard flow cell (Biolin Scientific, Sweden). (Having a sensor in place is required as a physical barrier to permit flow through the flow cell. The dummy sensor was used only to ensure thorough cleaning of the flow cell and tubing prior to installation of the test sensor.) Approximately 3-5 $\mathrm{ml}$ of $2 \mathrm{wt} \%$ SDS solution was introduced through the flow cell at $300 \mu \mathrm{L} / \mathrm{min}$ followed by $10-20 \mathrm{ml}$ of DI water at $300 \mu \mathrm{L} / \mathrm{min}$. The chamber or cell temperature was allowed to stabilize. Air was then flowed 
through the cell. The cell was disassembled, the dummy sensor was removed, the cell was dried with compressed, filtered air and then a pre-cleaned test sensor was positioned in the flow cell.

All prepared sensors were subjected to a standardized measurement protocol as follows. With a cleaned sensor in place, a particle-free background solution matching the salt concentration and $\mathrm{pH}$ of the test solution is introduced through the flow cell at $150 \mu \mathrm{L} / \mathrm{min}$ for 15 minutes. During flow, the chamber or cell temperature is checked for stabilization (set at $19^{\circ} \mathrm{C}$ ), and the resonant frequency and dissipation values are checked against their expected values and profiles/shapes (noise). Data acquisition for the background solution flowing at $150 \mu \mathrm{L} / \mathrm{min}$ is started and continues for 15 minutes to ensure a stable frequency baseline. The particle suspension of interest is then introduced and allowed to flow through the cell for 60 minutes. After the test period, the particle-free background solution is reintroduced at $150 \mu \mathrm{L} / \mathrm{min}$ for 15 minutes, allowing for any loose particles to be rinsed from the sensor surface. Data acquisition for the QCM measurement is stopped and then DI water is introduced at $300 \mu \mathrm{L} / \mathrm{min}$ for 10 minutes. The test sensor is removed from the cell and replaced with the dummy cleaning sensor. The flow cell is cleaned by flowing $2 \mathrm{wt} \%$ SDS at $300 \mu \mathrm{L} / \mathrm{min}$ for 15 minutes followed by flowing DI water at the same rate for a minimum of 30 minutes. Meanwhile, the test sensor is submerged into a series of static DI baths, whereby excess salt is rinsed off, thus allowing for particles adhered to the surface to be further characterized after drying.

\subsection{Surface Characterization}


The sensors were evaluated using an atomic force microscope (AFM) (Digital Instruments Dimension 3100, Billerica, MA) both before and after particle adsorption. High aspect ratio silicon tips (Veeco OTESPAW) were used to ensure accuracy of the AFM results and to minimize any tip convolution of the shapes measured. Instrument resolution was $\sim 10 \mathrm{~nm}$ and $\sim 1$ nm laterally for the $50 \mu \mathrm{m} \times 50 \mu \mathrm{m}$ and $5 \mu \mathrm{m} \times 5 \mu \mathrm{m}$ scans, respectively. The larger scan area was imaged where the particle concentration was low to ensure an accurate representation of the surface coverage; the smaller scan area was utilized for the high particle concentration solution experiments.

In an effort to quantify the extent of particle coverage, image analysis (using Image $\mathbf{J}$ software, National Institutes of Health) was performed by applying a threshold intensity to the particle images to create binary renderings such that the particles on the surface were dark pixels and the background was white. The areal coverage was calculated by counting the fraction of dark pixels in each image.

\section{Modeling}

\subsection{Kinetics model}

A simple Monte-Carlo model was developed to describe the kinetics of particle deposition. We assume that particles from the suspension reaching the surface have a probability of adsorption and that particles already adsorbed on the surface desorb at a fixed rate. We further assume that once a surface site is filled, it is no longer available for further adsorption. If $\mathrm{N}_{\text {tot }}$ is the total number of possible sites on the surface and $\mathrm{n}_{\mathrm{occ}}$ is the number of adsorbed particles on the surface, the rate at which the fill fraction $\phi=\mathrm{n}_{\text {ocd }} / \mathrm{N}_{\text {tot }}$ is changing is given by 


$$
\frac{d \phi}{d t}=p_{a d} J_{z} A(1-\phi)-v_{d} \phi
$$

Here $J_{z}$ the flux of particles onto the surface (particles/area-time), $p_{a d}$ is the probability of an incident particle adsorbing to the surface, $v_{\mathrm{d}}$ is the rate of desorption of an adsorbed particle, and $A$ is the area of a single surface site $\left(\mathrm{J}_{\mathrm{Z}} \mathrm{A}\right.$ is the number of particles incident on a site per unit time). At equilibrium, the surface fill fraction no longer changes with time and is described by the following expression.

$$
\phi_{\infty}=\frac{1}{1+\frac{v_{d}}{p_{a d} J_{z} A}}
$$

In the simulations, the surface fill fraction is determined as a function of time by repeatedly integrating Equation 1 for a time increment $\Delta \mathrm{t}$ with the number of incident particles given by the flux and the number of particles removed given by the desorption rate. The initial rate of deposition, when the fill fraction is low, is governed by the "deposition flux" (i.e. the net adsorbed incident flux, $p_{a d} J_{z} A$ ). The final fill fraction at equilibrium depends on the ratio of the desorption rate to the deposition flux. Two parameters are adjusted independently to achieve the best fit to the experimental data.

\subsection{Equilibrium colloidal stability model}

A basic colloidal stability model was used to probe the expected behavior of the colloid-surface interactions under various solution conditions. The model is based on the Derjaguin-LandauVerwey-Overbeek (DLVO) theory of colloidal stability and accounts for double-layer forces and van der Waals attraction. ${ }^{15}$ 
The van der Waals (vdW) interaction energy between a sphere of radius $\mathrm{R}$ and a flat surface, at separation distance $\mathrm{d}$, is given by

$$
W_{v d W}=-\frac{A_{H} R}{6 d}
$$

where $A_{H}$ is the Hamaker constant. The Hamaker constant was calculated using an approximate expression $^{15}$, assuming the nonretarded, symmetric case, where two identical macroscopic species 1 (silica, in this case) are separated by a medium 3 (salt solution):

$$
A_{H}=\frac{3}{4} k T\left(\frac{\varepsilon_{1}-\varepsilon_{3}}{\varepsilon_{1}+\varepsilon_{3}}\right)^{2}+\frac{3 h v_{e}}{16 \sqrt{2}} \frac{\left(n_{1}^{2}-n_{3}^{2}\right)^{2}}{\left(n_{1}^{2}+n_{3}^{2}\right)^{2 / 3}},
$$

where $\mathrm{k}$ is the Boltzmann constant, $\mathrm{T}$ is the temperature, $\varepsilon_{\mathrm{i}}$ is the relative permittivity of species $\mathrm{i}, \mathrm{n}_{\mathrm{i}}$ is the refractive index of species $\mathrm{i}, \mathrm{h}$ is Planck's constant, and $v_{\mathrm{e}}$ is the main electronic absorption frequency in the ultraviolet band, taken as $3.3 \times 10^{15} \mathrm{~s}^{-1}$. In the model, permittivity was adjusted based on ionic strength for both $\mathrm{NaCl}$ and $\mathrm{K}_{3} \mathrm{PO}_{4}$ solutions, as the permittivity of $\mathrm{NaCl}$ solutions has been shown to be linear up to $1 \mathrm{M}^{16}$ The refractive index of $\mathrm{NaCl}$ solutions was taken as a constant $\mathrm{n}=1.335$, because it varies $<0.4 \%$ over the range of molarities explored in this study. ${ }^{17}$

The electrical double layer interaction energy between a sphere and plate is given by

$$
W_{E D L}=R Z e^{-\kappa d},
$$

where $\kappa^{-1}$ is the Debye length,

$$
\kappa=\left(\sum_{i} \rho_{\infty i} e^{2} z_{i}^{2} / \varepsilon_{0} \varepsilon k T\right)^{1 / 2}
$$

which depends on the concentration $(\rho)$ and valence $(z)$ of the cation and anion in the solution; e is the elementary charge. $\mathrm{Z}$ is a surface-dependent interaction constant given by: ${ }^{15}$

$$
Z=64 \pi \varepsilon_{0} \varepsilon\left(\frac{k T}{z e}\right)^{2} \tanh ^{2}\left(\frac{z e \psi_{0}}{4 k T}\right)
$$


Equations 5 and 7 make use of the linear superposition approximation for the interaction of two surfaces of constant potential and are accurate only for separations beyond approximately one Debye length. ${ }^{15}$ In this study, the surface potential $\left(\psi_{0}\right)$ was approximated using the zeta potential of silica in the presence of $\mathrm{NaCl}$, which were interpolated and extrapolated from data

reported by Gaudin and Fuerstenau. ${ }^{18}$ Zeta potential was adjusted accordingly for each $\mathrm{pH}$ and $[\mathrm{NaCl}]$ being evaluated. The total interaction energy for an interacting sphere and plate is given by the sum of the results from Equations 3 and 5. A net positive interaction energy suggests that the interaction between the particle and surface will be repulsive.

\section{Results and Discussion}

A simplified model polishing system—silica spheres interacting with a flat silica surface—was chosen as a surrogate to evaluate slurry particle deposition onto silica work pieces under various conditions. The QCM-D was used to characterize both the degree and nature of in situ adsorption of silica colloids onto silica-coated sensors in an enclosed flow cell under identical flow conditions.

\subsection{Characterization of silica particle adsorption}

Figure 1 shows the change in both the sensor's normalized resonant frequency response and energy dissipation response as a function of time for a series of independent experiments (each on a new sensor) performed at $0.5 \mathrm{M} \mathrm{NaCl}$ and $\mathrm{pH} 8$ with concentrations of $100-\mathrm{nm}$ silica colloids ranging from $0.053 \mathrm{nM}-13.2 \mathrm{nM}$. As the QCM sensor gains mass through adsorption of colloids, the sensor's resonant frequency decreases with time, as shown in Figure 1a. After 
60 minutes of particle deposition, the background solution is reintroduced into the flow cell to remove any unbound or loosely bound colloids from the sensor surface. The change in frequency recorded after 15 minutes of rinsing is taken as the equilibrium frequency change. The frequency data shows little change upon rinsing with background solution, indicating that particles are bound to the sensor under the background conditions.

For clarity, we provide within the manuscript only the data obtained from oscillations at 15 $\mathrm{MHz}$, which is the third harmonic of the fundamental resonant frequency of the quartz sensor. However, data from the QCM-D was collected and examined for odd harmonics from $\mathrm{n}=3$ to $\mathrm{n}$ $=13$ to ensure consistent instrument response. Figure $\mathrm{S} 1$ shows representative data from these studies that demonstrate consistent responses with time across harmonics for 50-nm, 100-nm, and 300-nm silica particles. Olsson and coworkers observed that the frequency change trended positive at higher harmonics for silica particles adsorbing onto silica sensors at different ionic strengths and were able to explain this using a coupled resonance model. ${ }^{19}$ We did not observe this phenomenon (Figure S2); however, the diameters of the silica particles used in the present study are commensurate with the QCM-D instrument's film penetration depths $(<250-\mathrm{nm}$ and decreasing with increasing harmonic), whereas the Olsson study used $0.5-\mu \mathrm{m}$ and $2.5-\mu \mathrm{m}$ particles.

The data in Figure 1a shows that the rate of adsorption of silica particles increases with suspension particle concentration, as indicated by the increasing magnitude of the initial slopes $(\mathrm{d}(\Delta \mathrm{F}) / \mathrm{dt})$ associated with the introduction of particle suspensions as the particle concentration increases. Therefore, the final observed frequency change after 60 minutes of exposure to 
particles depends on the adsorbate concentration present in the suspension. No difference in the 60-min coverage is observed when 100 -nm particle concentrations in the suspension exceeded $5.3 \mathrm{nM}$, indicating that equilibrium deposition for this system is achievable within $60 \mathrm{~min}$ at concentrations $\geq 5.3 \mathrm{nM}$.

The decrease in resonant frequency is associated with an increase in mass loading on the sensor surface. However, the dissipation behavior of adsorbed particle layers is distinct from that of rigid, homogeneous films that do not dissipate energy. ${ }^{20}$ As discrete silica colloids deposit on the sensor, they dampen its vibration through various modes (e.g. rocking, sliding) ${ }^{21,22}$, resulting in an increase in measured energy dissipation (Figure 1b). As independent particles begin contacting one another, their ability to move relative to the sensor are reduced, thus decreasing the energy dissipation occurring at the liquid-particle boundary. The dissipation data shown in Figure 1b suggests that adsorbed 100-nm silica particles on silica surfaces behave in situ as discrete, non-contacting, entities at normalized frequency changes less than $\sim 530 \mathrm{~Hz}$, with dissipation increasing as more mass is deposited. However, the deposited particles appear to begin contacting one another when frequency changes exceed $\sim 530 \mathrm{~Hz}$. Their more restricted motion relative to the sensor surface becomes apparent at suspension particle concentrations of $5.3 \mathrm{nM}$ and $13.3 \mathrm{nM}$, where the dissipation curves exhibit a transient maximum with a subsequent reduction in dissipation response. This response is characteristic of the behavior of heterogeneously adsorbed spherical particles and has been shown to occur for other systems at $\sim 15 \%$ surface coverage. ${ }^{22}$ These results agree with Johannsmann's observations for dissipation in films of adsorbed nanospheres and extend the observations to the case of 100-nm rigid 
inorganic spheres interacting with a rigid inorganic surface, in the absence of compliant organic molecules.

Figure 2a-e show representative $5 \mu \mathrm{m}$ x $5 \mu \mathrm{m}$ AFM scans of the sensor surfaces after exposure to a series of suspension particle loadings corresponding to the experiments in Figure 1. Lineouts across the scans (example in Figure 2f) show that the feature sizes are consistent with 100-nm particles and that they are arranged in a monolayer over the sensor surface, with larger numbers of particles present on the surface as the suspension particle concentration increases. These images confirm that silica particle binding to the silica sensor surface is responsible for the observed changes in normalized frequency response and also show that a greater apparent fractional surface coverage is correlated with a larger change in frequency response. Furthermore, the AFM images (Figure $2 \mathrm{~d}$,e) that correspond to experiments with observed transient dissipation maximum in Figure $1 \mathrm{~b}$ show that clusters of particles are present. This provides evidence that increased particle contact correlates with a reduction in dissipation.

Figure 3a shows the AFM fractional coverage for several separate experiments conducted at 0.5 $\mathrm{M} \mathrm{NaCl}$ using 50-nm and 100-nm silica particles. The 50-nm and 100-nm particles are expected to fall on different curves, as frequency response of the sensor should change in proportion to particle mass. The frequency response for both particle sizes remains fairly linear at low coverage but deviates in linearity once the fractional coverage becomes large enough for particles to begin to interact with one another (e.g. 30\% coverage for 100-nm particles). Frequency response for other particle systems has been shown to be non-linear. The frequency saturates at high coverage due to reduction in volume of trapped solvent. ${ }^{23}$ 
The Sauerbrey equation relates the resonant frequency (f) of the quartz crystal to its thickness $t_{q}$ :

$$
\boldsymbol{f}=\boldsymbol{n} \frac{\mathrm{v}_{q}}{2 t_{q}}
$$

where $\mathrm{v}_{\mathrm{q}}$ is the shear wave velocity in quartz and $\mathrm{n}$ is the integer harmonic. ${ }^{24}$ For rigidly adsorbed, uniformly distributed layers, an observed change in resonant frequency $\Delta \mathrm{f}$ can be ascribed directly to a change in sensor thickness, which can be converted to mass per unit area $\Delta \mathrm{m}$ using the density:

$$
\Delta \boldsymbol{f}=-\boldsymbol{n} \frac{1}{C} \Delta m,
$$

where $\mathrm{C}$ is the Sauerbrey constant of $17.7 \mathrm{ng} /\left(\mathrm{cm}^{2}-\mathrm{Hz}\right)$. Because the silica colloids adsorb as isolated and discrete entities and exhibit appreciable dissipation as a function of frequency, Equation 9 does not hold at low coverage. ${ }^{24,25}$ In Figure 3b, the ratio of dissipation change to frequency change (DF ratio) is plotted as a function of frequency response for three different sized silica particles adsorbing to silica-coated sensors. Tellechea and coworkers showed that the thickness of heterogeneous films can be extracted by extrapolating the linear portion of these curves to determine the frequency intercept corresponding to zero dissipation; i.e., the expected value for $100 \%$ coverage (i.e. a homogeneous film). ${ }^{25}$ Best fits to the linear portions of the DFratio curves for the $3^{\text {rd }}$ overtone yield the frequency intercepts shown in Table 1 . In the limit of homogeneous coverage, Equation 8 applies and has been shown to provide reasonable thickness estimates for densely packed monolayers. Using a density of $2.2 \mathrm{~g} / \mathrm{cm}^{3}$ for the amorphous silica particles, these frequency intercepts predict film thicknesses of $40.2 \mathrm{~nm}, 76.2 \mathrm{~nm}$, and $273.5 \mathrm{~nm}$, respectively, for particles of 50-nm, 100-nm, and 300-nm in diameter. This is consistent with previous reports that the Sauerbrey equation underestimates film thicknesses by $\sim 20 \%$ for low- 
to-moderate coverage of heterogeneous species due to the presence of a hydration layer around the adsorbed species. ${ }^{23}$

The data from Figure 3a correlates the change in normalized frequency response with the fractional surface coverage. Using the linear portion of the curve, valid for coverage up to $\sim 30 \%$, the frequency response data in Figure 1a can be converted to surface coverage as a function of time. The kinetics model described in Section 3.1 is then used to predict the deposition response--the expected fill fraction as a function of time. The best fit to the data at each suspension concentration is determined by independently adjusting two parameters: the deposition flux and the desorption rate. The modeled deposition response is presented alongside the experimental data in Figure 4a. The agreement between the best fit curves and the data is good and suggests that the kinetics model reasonably describes the evolution of observed surface coverage over time. In addition, the simulated surface coverage maps from the end of the simulation (Figure 2) agree qualitatively with the AFM images from the experiments.

Figure $4 \mathrm{~b}$ shows the best fit deposition flux as a function of concentration of particles in the suspension. Note that deposition flux required to achieve the best fit increases with suspension concentration. The results imply that the particles arrive at the surface by a simple settling phenomenon, where the flux is given by concentration times the drift velocity. ${ }^{26}$ If the particles were instead arriving via diffusion-limited transport, where the diffusion coefficient decreases with increasing concentration ${ }^{27}$, the deposition flux would be expected to fall off with the concentration. This is not observed. Figure $4 \mathrm{c}$ shows that the relative desorption probability required to achieve the best fit to the data also increases with the particle concentration in the 
suspension, scaling with concentration to the 0.6 power. It is reasonable that the desorption probability would increase with increasing suspension concentration, as a greater propensity for interactions between surface particles and particles in suspension will alter the balance in the competition between particle sticking and particle desorption.

\subsection{Effect of ionic strength}

The effect of salt concentration on adsorption was also systematically explored. Figure 5a shows the 60-min frequency response for a series of independent experiments with varying $[\mathrm{NaCl}]$ that were conducted at $\mathrm{pH}$ 7-8 using 100-nm diameter silica particles at particle concentrations of both $2.65 \mathrm{nM}$ and $5.3 \mathrm{nM}$. Little adsorption takes place until the ionic strength exceeds about $0.4 \mathrm{M}$, beyond which there is a steep increase in the 60-min frequency response that appears to asymptote towards the extrapolated $100 \%$ coverage line at $947 \mathrm{~Hz}$ (Table 1). This behavior agrees qualitatively with the simple DLVO model described in Section 3. The model (Figure 5b) for 100-nm particles at $\mathrm{pH} 8$ predicts that the total interaction energy loses its repulsion peak and becomes entirely negative at ionic strengths between $0.3 \mathrm{M}-0.4 \mathrm{M}$, at which point adsorption between silica spheres and a silica plate becomes favorable. For ionic strength above $0.5 \mathrm{M}$, there is no significant change in the predicted total interaction energy that would predict an enhanced driving force for adsorption.

\subsection{Effect of suspension $\mathrm{pH}$}

In addition, $\mathrm{pH}$ was varied in a series of experiments with $100-\mathrm{nm}$ silica particles, and the results were compared with DLVO model predictions. The experimental results are summarized in Figure 6a. In all cases, the 60-min frequency response is near zero at high pH but increases 
(indicating increased adsorption) as the $\mathrm{pH}$ approaches the isoelectric point of silica, which is near $\mathrm{pH} 2$ at $[\mathrm{NaCl}]<0.1 \mathrm{M}$ but shifts toward $\mathrm{pH} 4$ at $[\mathrm{NaCl}]=0.4 \mathrm{M}^{28}$ The trend with $\mathrm{pH}$ observed for the particles at $0.2 \mathrm{M} \mathrm{NaCl}$ and $0.53 \mathrm{nM}$ particles is well predicted by the DLVO model at $0.2 \mathrm{M} \mathrm{NaCl}$, as shown in Figure $6 \mathrm{~b}$, where a decrease in the repulsive peak occurs at $\mathrm{pH}$ 7.2. At $\mathrm{pH}<7.2$, the total interaction energy shifts toward favorable adsorption and corresponds with the experimentally observed increase in adsorption below pH 7 .

This stands in stark contrast to the prediction for ionic strength $>0.4 \mathrm{M}$. The results of the DLVO model for $0.5 \mathrm{M} \mathrm{NaCl}$ are provided in Figure 6c, which shows that adsorption is favored at all values of $\mathrm{pH}$, with little difference in total interaction energy to be expected between $\mathrm{pH} 3$ and 10. The model result is dominated by greatly reduced variation in silica zeta potential across the $\mathrm{pH}$ range as the ionic strength increases. ${ }^{18,28}$ The QCM experimental data in Figure 6a seemingly contradicts the model prediction, as there is clearly more adsorption observed at low $\mathrm{pH}$ than high $\mathrm{pH}$, even at ionic strengths $\geq 0.5 \mathrm{M}$.

A number of assumptions made in the simple DLVO model may inadequately describe the system. For example, the zeta potential was extracted from Gaudin's results and was used as a surrogate for surface charge. In addition, an alternative non-DLVO force other than van der Waals attraction or electrostatic repulsion, such as short-range repulsive hydration forces ${ }^{29-31}$, may play a role under these conditions and therefore would need to be included in a more precise calculation of total interaction energy. This simple accounting may not provide an appropriate description of the particle-surface interaction. 
Nevertheless, the experimental results may be explained at least qualitatively using the existing model by considering the following. First, the model predicts negative interaction potential for both sphere-plate and sphere-sphere interactions, indicating that both particle adsorption onto the sensor and agglomeration between particles are favored at high ionic strength. To explore this, the apparent mean diameter of 100-nm silica particles was measured by dynamic light scattering (DLS) as a function of $\mathrm{NaCl}$ concentration near $\mathrm{pH}$ 8. Indeed, the results (Figure 7a) suggest that agglomerates begin to form in the suspensions at $\mathrm{NaCl}$ concentrations above $0.4 \mathrm{M}$ immediately after preparation.

Furthermore, either the final agglomerate size or the agglomeration kinetics appears to depend on $\mathrm{pH}$. Figure $7 \mathrm{~b}$ summarizes the results of DLS measurements of apparent mean diameter of 100$\mathrm{nm}$ silica particles as a function of $\mathrm{pH}$ for suspensions in $0.5 \mathrm{M} \mathrm{NaCl}$ and $0.1 \mathrm{M} \mathrm{K}_{3} \mathrm{PO}_{4}$. The particles appear to be $>2 \mathrm{x}$ larger at $\mathrm{pH} 4$ than at $\mathrm{pH} 10$. Therefore, in addition to adsorbing onto the QCM sensors, the particles agglomerate to some degree during the course of the adsorption experiments; additionally, the agglomerate size (or the kinetics of agglomeration) is $\mathrm{pH}$ dependent.

The apparent discrepancy between experimental results (Figure 6a) and model prediction (Figure 6c) with $\mathrm{pH}$ at high ionic strength can qualitatively be explained in terms of the observed agglomeration. The presence of agglomerates at high and low $\mathrm{pH}$, and their impact on adsorption, is depicted schematically in Figure 7c. Figure 7d shows the response of the DLVO model at $0.5 \mathrm{M} \mathrm{NaCl}$ and $\mathrm{pH} 4$ for particles with diameters of $100-\mathrm{nm}, 400-\mathrm{nm}$, and 800-nmsurrogates for agglomerates of various size. While the total interaction potential is negative in all 
cases, adsorption is more favorable for larger particles than for smaller ones, driven by increased van der Waals attraction. Thus, a suspension containing more agglomerated particles, or larger agglomerates, would be expected to have a larger adsorption response than one with no agglomerates. Because agglomerate size in high ionic strength suspensions increases as $\mathrm{pH}$ decreases, it is reasonable to expect that the frequency response-a measure of mass of adsorbed species—would also increase with decreasing $\mathrm{pH}$. Indeed, the results shown in Figure $6 \mathrm{a}$ at $\mathrm{pH}$ 4 at $0.6 \mathrm{M} \mathrm{NaCl}$ and $0.1 \mathrm{M} \mathrm{K}_{3} \mathrm{PO}_{4}$ have a greater-than-monolayer frequency response, indicating that these particles likely went onto the surface as agglomerates rather than single particles.

Figure 8 shows AFM images from sensors used in $\mathrm{pH}$ series experiments in $0.6 \mathrm{M} \mathrm{NaCl}$ and 0.1 $\mathrm{M} \mathrm{K}_{3} \mathrm{PO}_{4}$. The images confirm that the measured frequency response corresponds to increased surface adsorption with decreasing $\mathrm{pH}$. The images also suggest that there may be a propensity for agglomerated particles to adsorb preferentially, given that doubles and triples can be observed on the surface, even at $\mathrm{pH} 10$ when the surface coverage is very low. Interestingly though, the height profiles associated with the AFM images consistently show peak-to-valley deviations of $\sim 100$-nm — close to the single-particle height — suggesting coverage is only a monolayer, even on the samples evaluated at $\mathrm{pH}$ 4. This would not be expected if agglomerates were depositing on the sensor surface or based on the frequency responses at low $\mathrm{pH}$, which exceed the predicted $100 \%$ monolayer coverage frequency (cf. Figure $6 \mathrm{a}, 0.6 \mathrm{M} \mathrm{NaCl}$ and $0.1 \mathrm{M}$ $\mathrm{K}_{3} \mathrm{PO}_{4}$ at $\left.\mathrm{pH} 4\right)$.

This discrepancy can likely be attributed to a real surface difference between the in situ adsorption measured by the QCM frequency response and ex situ AFM imaging (cf. Figure 7c). 
QCM measurements are conducted with the sensors exposed only to salt-matched buffer, whereas in preparation for AFM imaging, the sensors are gently rinsed with water to prevent salt from crystallizing on the sensor surface thus affecting the topography. Exposure to DI water does not appreciably remove silica particles from the sensor surface. Per protocol, all sensors are rinsed with DI water in the flow cell and yet observed surface coverage remains proportional to the frequency response. However, exposure to DI water has been confirmed to cause a rapid breakup of agglomerates in the test suspensions. A one-week-old suspension of 100-nm silica particles in $0.6 \mathrm{M} \mathrm{NaCl}$ at $\mathrm{pH} 4.6$ was measured by DLS to have mean particle size of 1070 +/$40 \mathrm{~nm}$, but immediately after dilution with DI water, the mean particle size was measured to be $224+/-3 \mathrm{~nm}$. These results suggest that the agglomerates are weakly bound compared to the surface adsorption and also indicate that the in situ frequency response is a more reliable indicator of adsorption than the ex situ observations via AFM.

\subsection{Effect of Surface Roughness}

The impact of silica surface roughness on the propensity for particle adsorption was also studied experimentally. Silica-coated QCM sensor surfaces were intentionally roughened by two different techniques (as described in Section 2.2), and adsorption onto these roughened sensors was compared with the adsorption onto the unmodified sensor surfaces as-received from the vendor. Representative QCM responses are shown in Figure 9 for deposition of 50-nm or 100$\mathrm{nm}$ particles in $0.5 \mathrm{M} \mathrm{NaCl}$ onto the different sensor surfaces. In this series, the only difference in conditions was the sensor surfaces, which were either unmodified and used as-received, manually-ground with 30T grit alumina abrasive, or polished with ceria slurry. For both 50-nm and 100-nm particle sizes, the sensors that had been roughened using the ceria polishing method 
exhibited larger 60-min frequency responses than they did for the silica sensors as-received from the vendor under identical suspension conditions. Chemical analysis by scanning electron microscopy with energy dispersive spectroscopy (EDS) (data not shown) confirmed that silica remains on the sensor surfaces roughened by both techniques. While we cannot completely rule out that some polishing compound remained on the sensor surfaces, little-to-none of the alumina or ceria polishing compounds was found to be present on the surfaces of the $30 \mathrm{~T}$ roughened and ceria-polishing roughened samples using EDS. Thus, it is likely that the experimental responses can be attributed largely to changes in surface roughness rather than to large-scale chemical changes over the sensor surface from adsorbed polishing compound.

Representative 5- $\mu \mathrm{m} \times 5-\mu \mathrm{m}$ AFM images of sensors, before and after adsorption of 50-nm or 100-nm particles, are displayed in Figure 10. The average surface roughness of the as-received sensors was $1.3 \pm 0.3 \mathrm{~nm}$ root-mean-square (rms) across 5 different silica coated sensors in the 5 $\mu \mathrm{m}$ x 5- $\mu \mathrm{m}$ AFM scale and $2.4 \AA$ rms over a 1-mm x 1.2-mm area interrogated by white light interferometry (Figure S3). White light microscopy (Figure S3) for sensors roughened using the 30T grit alumina abrasive revealed that they had been scratched and pitted over the entire active sensing surface, with lengths ranging from microns to $0.5 \mathrm{~mm}$. AFM scans performed on $50-\mu \mathrm{m}$ $\mathrm{x} 50-\mu \mathrm{m}$ areas to interrogate the scratches reveal that the deepest scratches were approximately $150 \mathrm{~nm}$ deep and up to $3 \mu \mathrm{m}$ wide. These sensors showed little change in surface roughness at

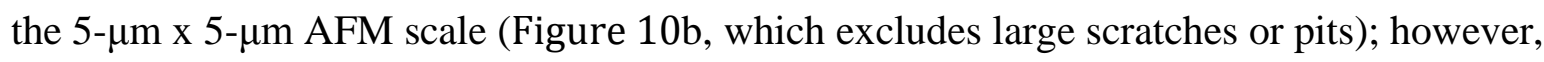
roughness increased to $7 \mathrm{~nm}$ rms over a 1-mm x 1.2-mm area as measured by white light interferometry. 
White light microscopy on the ceria-polished sensors showed that the scratches imparted by this technique were present over the entire active sensing surface and were consistently millimeters long. Scratch depths were interrogated by AFM over $50-\mu \mathrm{m}$ x $50-\mu \mathrm{m}$ areas. A subset of scratches were 100-150 nm deep and $3 \mu \mathrm{m}$ wide; however, the majority of scratches imparted by this technique were 3-20 $\mathrm{nm}$ deep and 100-300 $\mathrm{nm}$ wide with a high number density. These fine scratches were uniformly present at the 5- $\mu \mathrm{m} \times 5-\mu \mathrm{m}$ AFM scale and increased the surface roughness to $2.7 \mathrm{~nm} \mathrm{rms}$ at that scale. The roughness was increased to $17 \mathrm{~nm} \mathrm{rms}$ over the $1-\mathrm{mm}$ x 1.2-mm interferometry scale (Figure S3).

The results on the 30T alumina abrasive roughened sensors were mixed. The frequency response (Figure 9) was 30\% greater than the baseline response for the as-received sensor for the 50-nm silica particles; however, the response was $40 \%$ lower than the baseline for the $100-\mathrm{nm}$ silica particles. Although the adsorption responses differed depending on the introduced particle size, it is unlikely that particle size itself played a large role in this case. The 3 - $\mu$ m width of the scratches or pits, characteristic features of the 30T grit roughened samples, greatly exceed both the particle diameter (50-nm or $100-\mathrm{nm})$ and the $400-\mathrm{nm}$ average agglomerate size for the 100 $\mathrm{nm}$ particles. The $50-\mathrm{nm}$ particles in $0.5 \mathrm{M} \mathrm{NaCl}$ did not appear agglomerated when measured by DLS. Thus, the scratches have low curvature in comparison to the particle, and thus would be expected to behave as a flat surface.

It should be noted that scratches deeper than $\sim 50 \mathrm{~nm}$ will have exposed some of the adhesion layer and gold electrode layer on the QCM sensor creating a gold-silica interaction; however, this would be a small fraction of the total exposed sensor surface area and should be 
approximately the same for both silica particle sizes. More likely, the mixed 30T result is due to the variability in the roughening process over the sensor area and from sensor to sensor. $\mathrm{A} \pm 30 \%$ variation in the number density and/or lengths of scratches from sensor to sensor is reasonable for this manual roughening process and would affect the total silica surface area available for adsorption of these smaller-than-feature scale particles.

In contrast, the levels of adsorption reached on the ceria-polished sensors - in terms of frequency response and observed sensor coverage - far exceeded adsorption levels observed under any suspension conditions used on the as-received sensors. This was especially apparent in the case of the 50-nm diameter silica particles (Figure 10f), where nearly 100\% coverage of the sensor was observed via AFM. The frequency responses were also higher than the responses on the asreceived sensors: $280 \%$ higher for 50-nm diameter particles and 130\% higher for 100-nm diameter particles. In this case, the particle diameter and agglomerate sizes are commensurate with the scratch depths and widths. The dominant roughness features of the ceria-polished samples were 3-20 nm deep and 100-300 nm wide and were consistent over long scale lengths as well as routinely present in 5- $\mu \mathrm{m}$ x 5- $\mu \mathrm{m}$ AFM scans. Thus, the silica particles and even fewparticle agglomerates can penetrate to some depth within a scratch, which leads to an overall decrease in the total separation distance between particle and surface and would tend to enhance particle-surface attraction.

Extended DLVO models accounting for roughness give credence to these observations. A surface roughness of 2-nm rms at the AFM scale can increase the attractive van der Waals force for a sphere-plate interaction by $\sim 10-25 \% .{ }^{32}$ In addition, the height of the repulsive barrier is 
reduced for roughened surfaces compared with smooth surfaces and the amount of the reduction is correlated with the magnitude of the roughness. ${ }^{33}$ Furthermore, the adsorbate size relative to the feature size is expected to play a large role. Hoek and Agrawal found that the interaction potential can be enhanced by up to $5 x$ compared to the sphere-plate DLVO prediction when a particle enters a negative asperity because the effective separation distance over the interaction

area is greatly reduced. ${ }^{34}$ This suggests that the wide, deep scratches, which were present in both roughened systems, did not play a dominant role in the adsorption and that the most relevant roughness scale length to consider for the DLVO interaction is the fine scale roughness at the 5$\mu \mathrm{m} \times 5-\mu \mathrm{m}$ AFM scale length. By this measure, the 30T grit-roughened sensors had approximately equivalent roughness to the as-received sensors and would be expected to yield a similar frequency response, whereas the ceria-polished sensors were nearly $2 \mathrm{x}$ as rough and an adsorption increase could be expected. In fact, the ceria-polished sensors showed a large increase in adsorption relative to the as-received sensors, whereas the $30 \mathrm{~T}$ grit response was relatively small and mixed. This implies that both the relative scale of roughness and the size of the adsorbate of interest must be taken into account in addition to the surface and suspension chemistries when considering adsorption or re-deposition in polishing systems.

\section{Conclusions}

QCM-D has been shown to be a viable platform both for assessing polishing interactions between slurry constituents and the work piece and for evaluating the role of polished surface roughness on adsorption. The adsorption of 50-nm and 100-nm silica particles onto like-charged silica surfaces were studied under a variety of suspension conditions and quantified by QCM-D and by AFM. Frequency responses were demonstrated to be proportional to observed surface 
coverage and were deemed to be a more reliable predictor of adsorption than the ex situ AFM, which did not accurately reflect surface agglomerates. Dissipation responses could be linked to particle distributions on the sensor surface, and particle sizes could be reasonably predicted by extracting layer thicknesses from the QCM-D responses.

A simple Monte Carlo model was used to model the deposition kinetics and showed that the flux of particles to the surface scales with concentration and appears to be governed by particle settling, and the probability of desorption increases with concentration to the 0.6 power. The onset of major adsorption with changes in ionic strength was predicted by an equilibrium DLVO model. Experimental observations differed from the model prediction for how adsorption should scale with $\mathrm{pH}$ at high ionic strength. Consideration of particle-particle agglomeration in addition to particle-surface interactions can resolve the discrepancy.

In addition, two new methods for roughening QCM-D sensor substrates were demonstrated, which enabled study of the impact of substrate roughness on the observed adsorption. It was found that the a change in silica surface roughness at the AFM scale from $1.3 \mathrm{~nm}$ rms to $2.7 \mathrm{~nm}$ rms resulted in an increase in silica particle adsorption by almost 3-fold for 50-nm diameter particles and 1.3-fold for 100-nm diameter particles - far exceeding adsorption observed by altering suspension conditions alone. The experimental results suggest that the roughness scale relative to the size of the adsorbate of interest likely plays a role in adsorption or re-deposition in polishing systems.

\section{Acknowledgements}


The authors would like to thank Edwin Sedillo for performing the scanning electron microscopy.

This work was performed under the auspices of the US Department of Energy by Lawrence

Livermore National Laboratory under Contract DE-AC52-07NA27344 within the LDRD

program. LLNL-JRNL-707117-DRAFT.

\section{Appendix A. Supplementary data}

Supplementary data associated with this article can be found, in the online version, at

\section{References}

1. A.A. Tesar, B.A. Fuchs, P.P. Hed, Applied Optics 1992, 31, 7164-7173.

2. T. Suratwala, M.D. Feit, W.A. Steele, L.L. Wong, J. Am. Cer. Soc. 2014, 97, 1720-1727.

3. T. Suratwala, P.E. Miller, J.D. Bude, W.A. Steele, N. Shen, M.V. Monticelli, M.D. Feit, T.A. Laurence, M.A. Norton, C.W. Carr, L.L. Wong, J. Am. Cer. Soc. 2010, 94, 416-428.

4. T. Suratwala, R. Steele, M. Feit, N. Shen, L. Wong, R. Dylla-Spears, R. Desjardin, S. Elhadj, P. Miller, submitted to J. Am. Cer. Soc. October 2016.

5. C.M. Cuppett, L.J. Doneski, M.J. Wirth, Langmuir 2000, 16, 7279-7284.

6. H. Ogi, Proc. Japan Acad. Series B-Phys. and Biol. Sci. 2-13, 89,401-417.

7. A.Y. Sham, S.M. Notley, Soft Matter 2013, 9, 6645-6653.

8. R.E. Speight, M.A. Cooper, J. Molec. Recognition 2012, 25, 451-473.

9. Q. Chen, S. Xu, Q. Liu, J. Masliyah, Z. Xu, Adv. Colloid Interface Sci. 2016, 233, 94114.

10. X. Liu, G. Chen, C. Su, Env. Sci. Tech. 2012, 46, 6681-6688.

11. H. Guleryuz, I. Kaus, C.C. Buron, C. Filiatre, N. Hedin, L. Bergstrom, M.A. Einarsrud, Colloids and Surfaces A: Physicochemical and engineering aspects 2014, 443, 384 -390.

12. J. Fatisson, R.F. Domingos, K.J. Wilkinson, N. Tufenkji, Langmuir 2009, 25, 6062-6069. 
13. T. Suratwala, R. Steele, M. Feit, L. Wong, P. Miller, J. Menapace, P. Davis, J. NonCrystalline Solids 2008, 354, 2023-2037.

14. T. Suratwala, R. Steele, M. Feit, R. Desjardin, D. Mason, International J. Applied Glass Sci. 2012, 3, 14-28.

15. J.N. Israelachvili, Intermolecular and Surfaces Forces 2011, 3rd edition, Academic Press, San Diego, Ch.13-15.

16. J.B. Hasted, D.M. Ritson, C.H. Collie, J. Chem. Phys. 1948, 16, 1-21.

17. D.R. Lide, ed., CRC Handbook of Chemistry and Physics 2016, $96^{\text {th }}$ edition, CRC Press, Section 5: Concentrative Properties of Aqueous Solutions.

18. A.M. Gaudin, D.W. Fuerstenau, Mining Engineering 1955, 7, 66-72.

19. A.L.J. Olsson, H.C. van de Mei, D. Johannsmann, H.J. Busscher, P.K. Sharma, Anal. Chem. 2012, 84, 4504-4512.

20. I. Reviakine, D. Johannsmann, R.P. Richter. Anal. Chem. 2011, 83, 8838-8848.

21. D. Johannsmann, I. Reviakine, E. Rojas, M. Gallego, Anal. Chem. 2008, 80, 8891-8899.

22. D. Johannsmann, I. Reviakine, R.P. Richter, Anal. Chem. 2009, 81, 8167-8176.

23. P. Bingen, G. Wang, N.F. Steinmetz, M. Rodahl, R.P. Richter, Anal. Chem. 2008, 80, 8880-8890.

24. F. Höök, Development of a novel QCM technique for protein adsorption studies, $\mathrm{PhD}$ Thesis, 1997, Chalmers University of Technology.

25. E. Tellechea, D. Johannsmann, N.F. Steinmetz, R.P. Richter, I. Reviakine, Langmuir 2009, 25, 5177-5184.

26. H. Lamb, Hydrodynamics, 6th ed.,1994, Cambridge University Press, p. 599.

27. W.R. Bowen, Y. Liang, P.M. Williams, Chem. Eng. Sci. 2000, 55, 2359-2377.

28. G.V. Franks, J. of Colloid and Interface Sci. 2002, 249, 44-51.

29. J.P. Chapel, Langmuir 1994,10,4237-4243.

30. J. Seo, J.H. Kim, M. Lee, J. Moon, D.K. Yi, U. Paik, J. Colloid Interface Sci. 2016, 483, $177-184$.

31. A. Grabbe, R.G. Horn, J. Colloid Interface Sci. 1993, 157, 375-383. 
32. J.L.M.J. Van Bree, J.A. Poulis, B.J. Verhaar, Physica 1974, 78, 187-190.

33. E.M.V. Hoek, S. Bhattacharjee, M. Elimelech, Langmuir 2003, 19, 4836-4847.

34. E.M.V. Hoek, G.K. Agarwal, J. Colloid Interface Sci. 2006, 298, 50-58. 


\section{Tables}

Table 1. Best fit frequency intercept and corresponding predicted Sauerbrey monolayer thickness for each particle size found using the $3^{\text {rd }}$ overtone and assuming a silica density of $2.2 \mathrm{~g} / \mathrm{cm}^{3}$.

\begin{tabular}{ccc}
\hline $\begin{array}{c}\text { Nominal } \\
\text { Particle Size } \\
(\mathrm{nm})\end{array}$ & $\begin{array}{c}\text { Frequency } \\
\text { Intercept } \\
(\mathrm{Hz})\end{array}$ & $\begin{array}{c}\text { Predicted } \\
\text { Sauerbrey } \\
\text { Thickness } \\
(\mathrm{nm})\end{array}$ \\
\hline 50 & 500 & 40.2 \\
\hline 100 & 947 & 76.2 \\
\hline 300 & 3400 & 273.5 \\
\hline
\end{tabular}


Figures
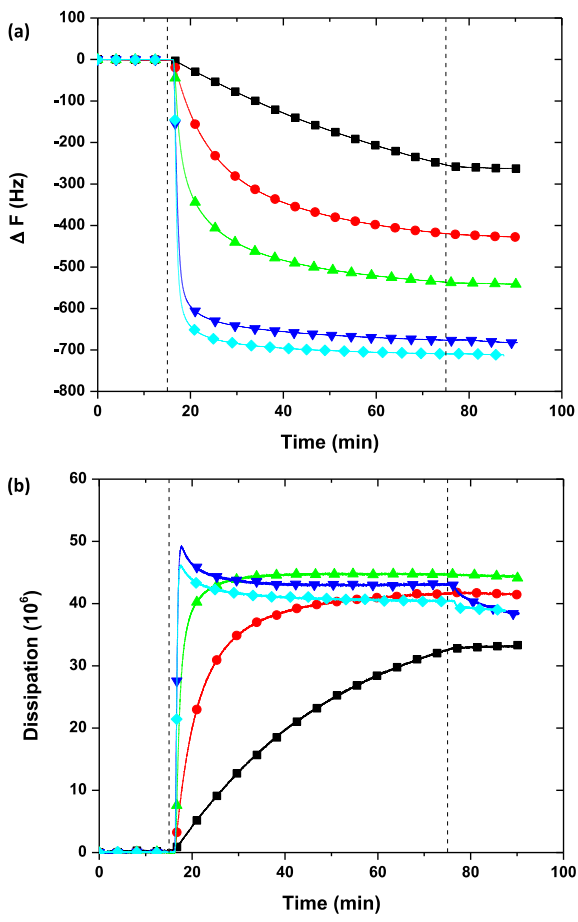

Figure 1. (a) Representative changes in normalized QCM frequency $(\Delta F=\Delta f / n, n=3)$ over time and (b) corresponding QCM dissipation responses obtained while flowing aqueous suspensions containing $0.5 \mathrm{M} \mathrm{NaCl}$ and various concentrations of $100-\mathrm{nm}$ silica particles at pH 8 over silica-coated QCM sensors: squares, $0.053 \mathrm{nM}$; circles, $0.53 \mathrm{nM}$; upward triangles, $2.65 \mathrm{nM}$; downward triangles, $5.3 \mathrm{nM}$; diamonds, $13.25 \mathrm{nM}$. The dashed vertical lines in both plots denote times corresponding to the introduction of particle suspension and the re-introduction of $0.5 \mathrm{M} \mathrm{NaCl}$ background solution.

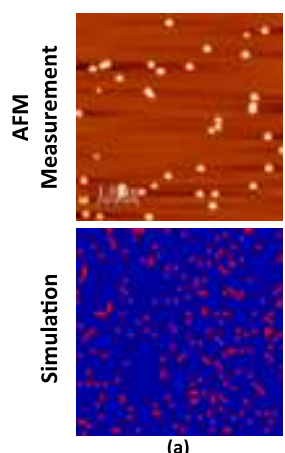

(a)

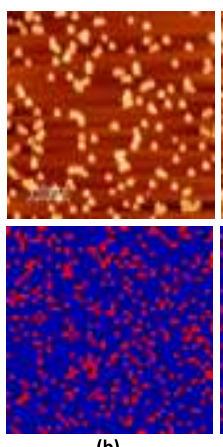

(b)

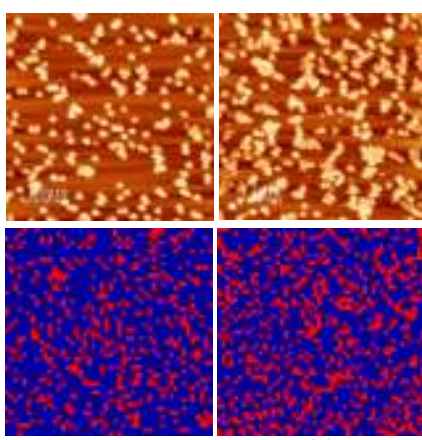

(c)

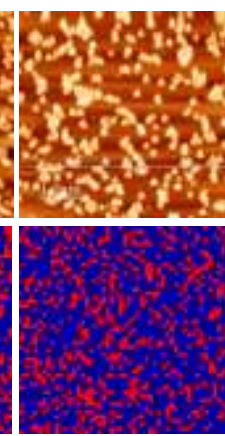

(e)

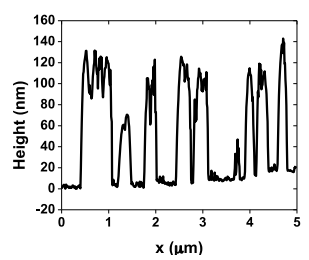

(f)

Figure 2. Representative $5 \mu \mathrm{m} \times 5 \mu \mathrm{m}$ AFM images (top row) of silica-coated QCM sensor surfaces after adsorption of $100-\mathrm{nm}$ silica particles from suspensions containing (a) 0.053 
$\mathrm{nM}$, (b) $0.53 \mathrm{nM}$, (c) $2.65 \mathrm{nM}$, (d) $5.3 \mathrm{nM}$, or (e) $13.25 \mathrm{nM}$ silica particles. Bottom row: Monte Carlo simulation result for each experiment. (f) Height profile across line shown in AFM image in (e).
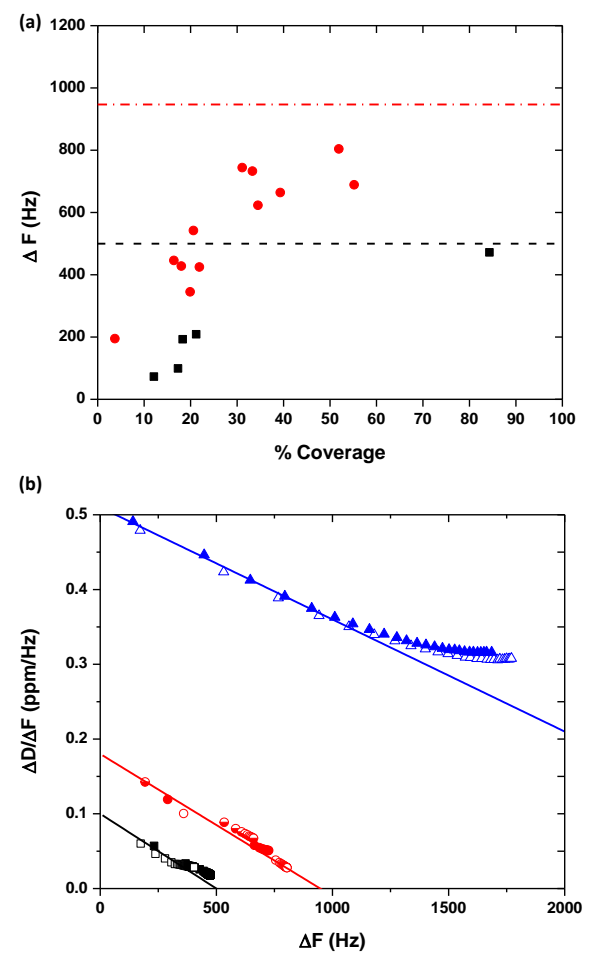

Figure 3. (a) Normalized 60-min QCM frequency change $\left(3^{\text {rd }}\right.$ harmonic) with AFMobserved sensor coverage area for 50-nm silica particles (squares) and 100-nm silica particles (circles) in $0.5 \mathrm{M} \mathrm{NaCl}$. Dashed lines represent $100 \%$ monolayer coverage predictions from Table 1 for each particle size. (b) Dissipation-to-frequency change ratio $\left(3^{\text {rd }}\right.$ harmonic) as a function of equilibrium frequency response for $50-\mathrm{nm}$ (squares), 100nm (circles), and 300-nm (triangles) silica particles. Different symbol fills represent replicate experiments using the same sized particles. Solid lines represent the best linear fit for each particle size in the linear region.

(a)

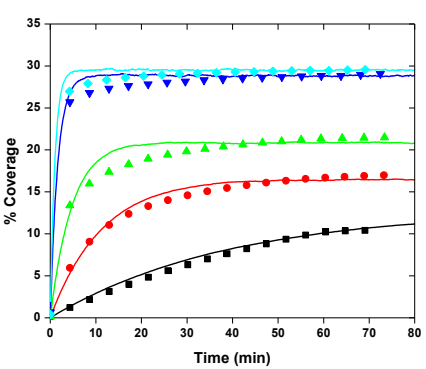

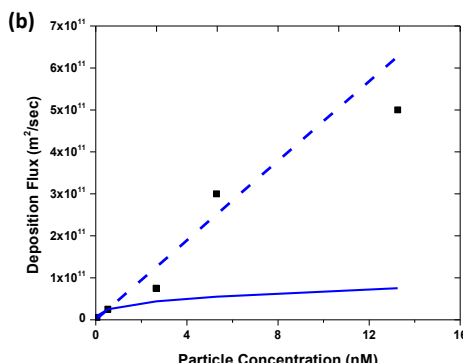

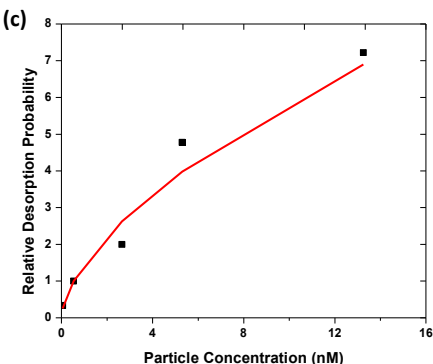

Figure 4. Results of kinetics model: (a) Best fit fractional surface coverage (solid lines) for each data set from the $0.5 \mathrm{M} \mathrm{NaCl}, 100-\mathrm{nm}$ silica particle concentration series: squares, 
$0.053 \mathrm{nM}$; circles, $0.53 \mathrm{nM}$; upward triangles, $2.65 \mathrm{nM}$; downward triangles, $5.3 \mathrm{nM}$; diamonds, $13.25 \mathrm{nM}$. (b) Symbols are the deposition flux used to achieve the best fit result in (a) for each particle concentration. Lines represent the expected scaling based on either settling (dashed) or diffusion (solid). (c) Symbols are the desorption probability used to achieve the best fit result in (a) at each particle concentration. Solid line is $y=x^{0.6}$.
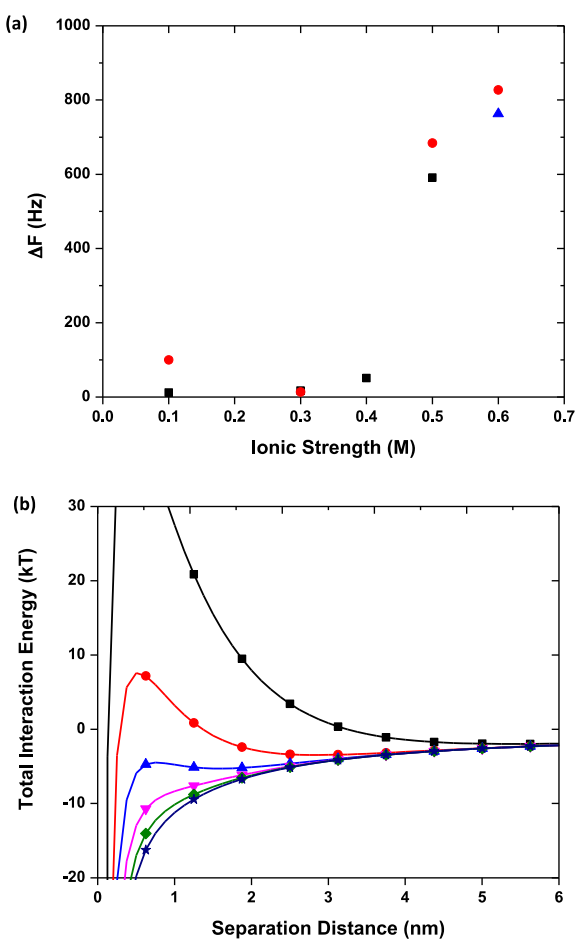

Figure 5. (a) Normalized frequency change $\left(3^{\text {rd }}\right.$ harmonic) after 60-min adsorption of 100$\mathrm{nm}$ silica particles onto silica sensors measured in separate experiments at various ionic strengths at pH 8: $2.65 \mathrm{nM}$ particles in $\mathrm{NaCl}$ (squares), $5.3 \mathrm{nM}$ particles in $\mathrm{NaCl}$ (circles), $5.3 \mathrm{nM}$ particles in $\mathrm{K}_{3} \mathrm{PO}_{4}$ (triangles). (b) Interaction energy versus separation distance calculated by DLVO model for 100-nm silica particles at $\mathrm{pH} 8$ and $\mathrm{NaCl}$ at $\mathrm{O.1} \mathrm{M}$ (squares), $0.2 \mathrm{M}$ (circles), $0.3 \mathrm{M}$ (upward triangles), $0.4 \mathrm{M}$ (downward triangles), $0.5 \mathrm{M}$ (diamonds), 0.6 M (stars).
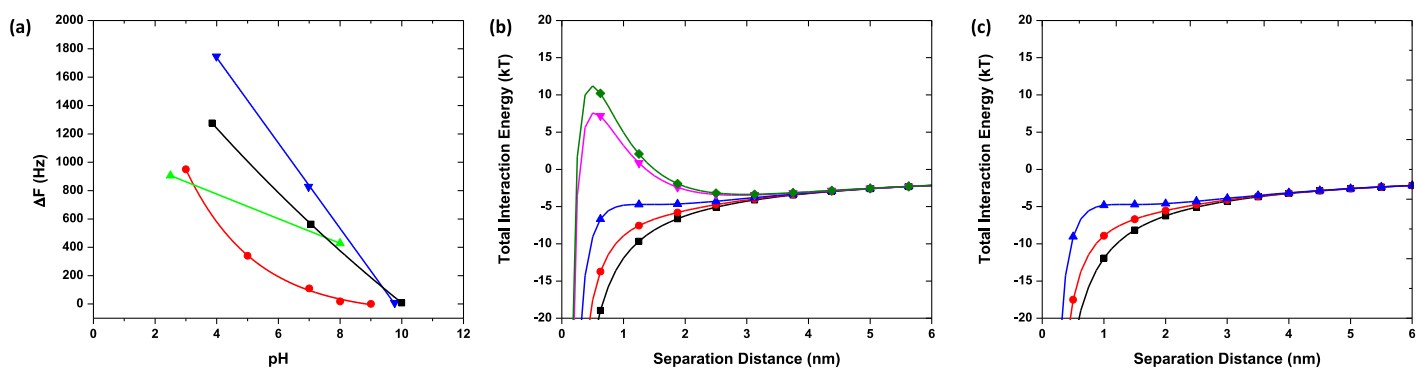
Figure 6. (a) Normalized frequency change $\left(3^{\text {rd }}\right.$ harmonic) after 60-min deposition of 100$\mathrm{nm}$ silica particles onto silica sensors as measured in separate experiments as a function of pH. Lines are provided as a guide to the eye: $0.53 \mathrm{nM}$ particles in $0.2 \mathrm{M} \mathrm{NaCl}$ (circles) or $0.5 \mathrm{M} \mathrm{NaCl}$ (upward triangles); $5.3 \mathrm{nM}$ particles in $0.6 \mathrm{M} \mathrm{NaCl}$ (downward triangles) or in $0.1 \mathrm{M} \mathrm{K}_{3} \mathrm{PO}_{4}$ (squares). (b,c) Interaction energy versus separation distance calculated using DLVO model for (b) 100-nm silica particles in $0.2 \mathrm{M} \mathrm{NaCl}$ at $\mathrm{pH} 4$ (squares), $\mathrm{pH} 6$ (circles), pH 7.2 (upward triangles), pH 8 (downward triangles), pH 10 (diamonds); (c) 100$\mathrm{nm}$ silica particles in $0.5 \mathrm{M} \mathrm{NaCl}$ at pH 4 (squares), pH 7 (circles), pH 10 (upward triangles).

(a)

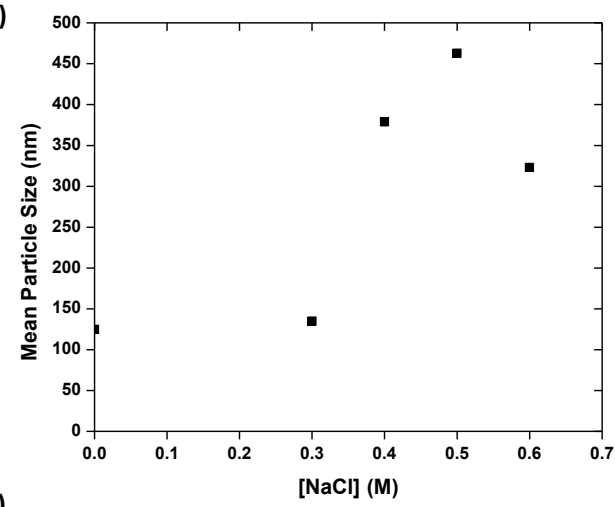

(c)

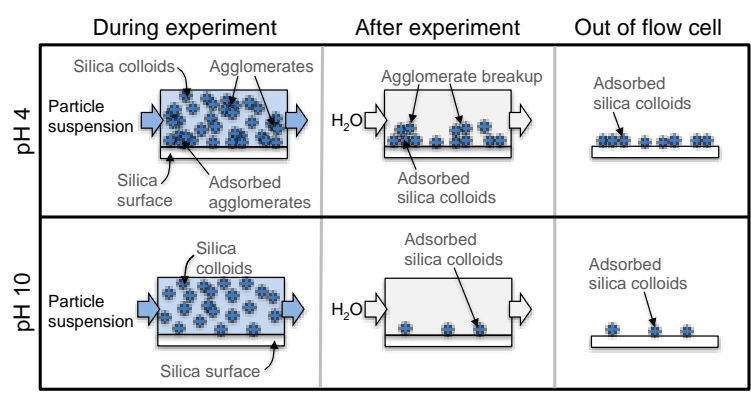

(b)
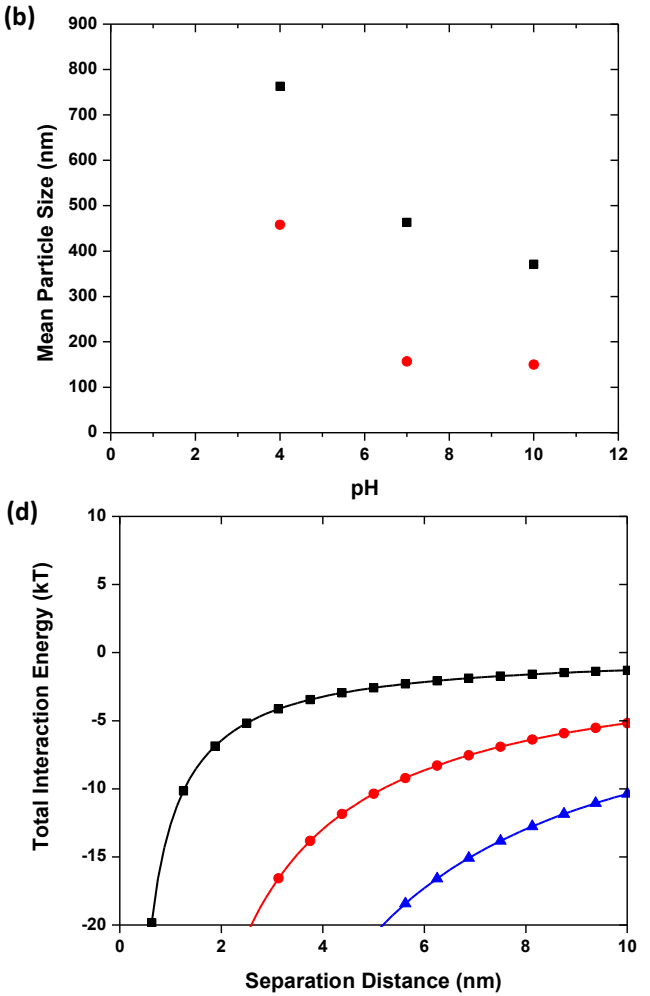

Figure 7. (a) Mean particle size measured by DLS for $100-\mathrm{nm}$ silica particles at $\mathrm{pH} 7$ as a function of $\mathrm{NaCl}$ concentration. (b) Mean particle size measured by DLS for 100-nm silica particles as a function of $\mathrm{pH}$ in either $0.5 \mathrm{M} \mathrm{NaCl}$ (squares) or $0.1 \mathrm{M} \mathrm{K}_{3} \mathrm{PO}_{4}$ (circles). (c) Schematic describing agglomeration formation during experiment and breakup of agglomerates prior to AFM measurement. (d) Interaction energy versus separation distance calculated using DLVO model for various silica particle diameters in $0.5 \mathrm{M} \mathrm{NaCl}$ at pH 4: $100 \mathrm{~nm}$ (squares), $400 \mathrm{~nm}$ (circles), $800 \mathrm{~nm}$ (triangles). 


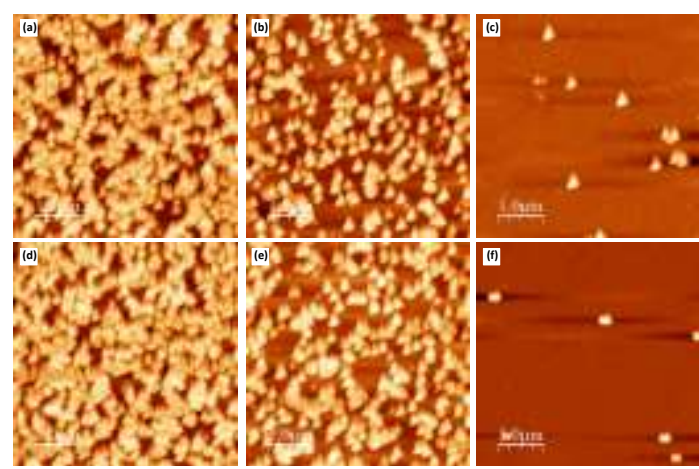

Figure 8. Representative $5 \mu \mathrm{m}$ x $5 \mu \mathrm{m}$ AFM scans from separate experiments showing deposition onto silica sensors from suspensions of $5.3 \mathrm{nM} 100-\mathrm{nm}$ silica particles in $0.6 \mathrm{M}$ $\mathrm{NaCl}$ (top row) at: (a) pH 4, (b) pH 7, (c) pH 10, and in $0.1 \mathrm{M} \mathrm{K}_{3} \mathrm{PO}_{4}$ (bottom row) at: (d) pH 4, (e) pH 7, (f) pH 10.

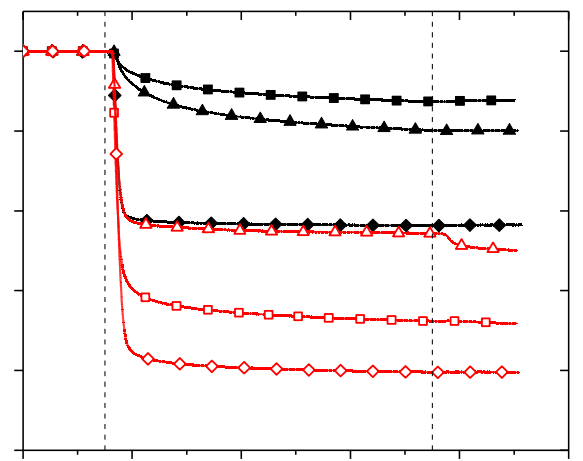

Figure 9. Normalized QCM frequency change responses $\left(3^{\text {rd }}\right.$ harmonic) for adsorption of $5.3 \mathrm{nM} 100-\mathrm{nm}$ silica particles (open symbols) or $21.1 \mathrm{nM} \mathrm{50-nm} \mathrm{silica} \mathrm{particles} \mathrm{(closed}$ symbols) suspended in $0.5 \mathrm{M} \mathrm{NaCl}$ at $\mathrm{pH} 8$ onto silica-coated QCM sensors: as-received (squares), roughened with 30T grit (triangles), or polished with ceria polishing slurry (diamonds). Dashed vertical lines denote times corresponding to the introduction of particle suspension and the re-introduction of $0.5 \mathrm{M} \mathrm{NaCl}$ background solution. 


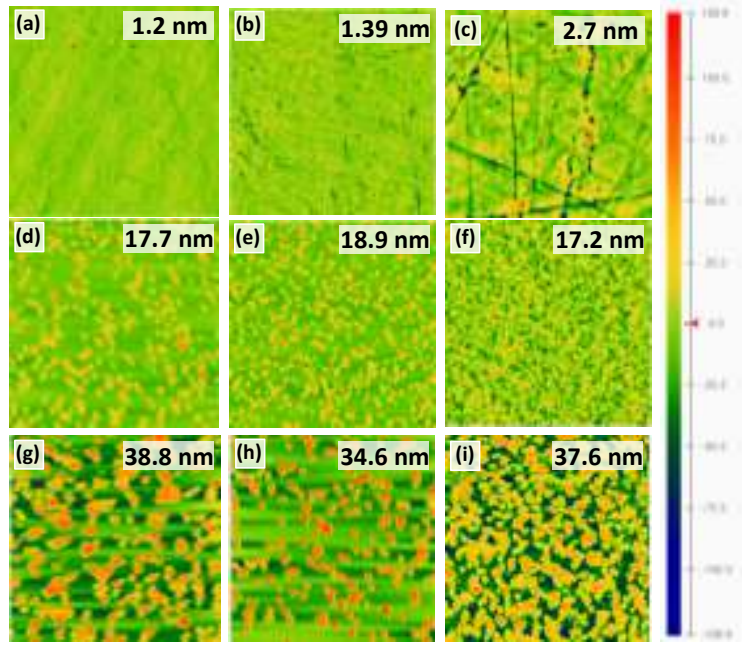

Figure 10. Representative $5 \mu \mathrm{m}$ x $5 \mu \mathrm{m}$ AFM scans showing height maps of silica-coated QCM sensor surfaces. Columns, left to right: as-received, 30T grit-roughened, and ceriaslurry polished. Note that columns do not represent repeat scans of the same area. Sensor surfaces (a-c) before QCM adsorption experiments, (d-f) after adsorption of $21.1 \mathrm{nM} 50$ $\mathrm{nm}$ silica particles suspended in $0.5 \mathrm{M} \mathrm{NaCl}$ at $\mathrm{pH} 8$, (g-i) after adsorption of $5.3 \mathrm{nM} 100$ $\mathrm{nm}$ silica particles suspended in $0.5 \mathrm{M} \mathrm{NaCl}$ at $\mathrm{pH}$ 8. Corresponding rms roughness is shown on each image. Color scale bar represents $-125 \mathrm{~nm}$ to $+125 \mathrm{~nm}$. (COLOR IN PRINT) 
Figure 4. Results of kinetics model: (a) Best fit fractional surface coverage (solid lines) for each data set from the $0.5 \mathrm{M} \mathrm{NaCl}, 100-\mathrm{nm}$ silica particle concentration series: squares, $0.053 \mathrm{nM}$; circles, $0.53 \mathrm{nM}$; upward triangles, $2.65 \mathrm{nM}$; downward triangles, $5.3 \mathrm{nM}$; diamonds, $13.25 \mathrm{nM}$. (b) Symbols are the deposition flux used to achieve the best fit result in (a) for each particle concentration. Lines represent the expected scaling based on either settling (dashed) or diffusion (solid). (c) Symbols are the desorption probability used to achieve the best fit result in (a) at each particle concentration. Solid line is $y=x^{0.6}$.

Figure 5. (a) Normalized frequency change ( $3^{\text {rd }}$ harmonic) after 60-min adsorption of 100$\mathrm{nm}$ silica particles onto silica sensors measured in separate experiments at various ionic strengths at $\mathrm{pH}$ 8: $2.65 \mathrm{nM}$ particles in $\mathrm{NaCl}$ (squares), $5.3 \mathrm{nM}$ particles in $\mathrm{NaCl}$ (circles), 5.3 nM particles in $\mathrm{K}_{3} \mathrm{PO}_{4}$ (triangles). (b) Interaction energy versus separation distance calculated by DLVO model for $100-\mathrm{nm}$ silica particles at $\mathrm{pH} 8$ and $\mathrm{NaCl}$ at $0.1 \mathrm{M}$ (squares), $0.2 \mathrm{M}$ (circles), 0.3 M (upward triangles), 0.4 M (downward triangles), $0.5 \mathrm{M}$ (diamonds), $0.6 \mathrm{M}$ (stars).

Figure 6. (a) Normalized frequency change ( $3^{\text {rd }}$ harmonic) after 60 -min deposition of 100$\mathrm{nm}$ silica particles onto silica sensors as measured in separate experiments as a function of $\mathrm{pH}$. Lines are provided as a guide to the eye: $0.53 \mathrm{nM}$ particles in $0.2 \mathrm{M} \mathrm{NaCl}$ (circles) or 0.5 $\mathrm{M} \mathrm{NaCl}$ (upward triangles); $5.3 \mathrm{nM}$ particles in $0.6 \mathrm{M} \mathrm{NaCl}$ (downward triangles) or in $0.1 \mathrm{M}$ $\mathrm{K}_{3} \mathrm{PO}_{4}$ (squares). (b,c) Interaction energy versus separation distance calculated using DLVO model for (b) 100-nm silica particles in $0.2 \mathrm{M} \mathrm{NaCl}$ at pH 4 (squares), $\mathrm{pH} 6$ (circles), pH 7.2 (upward triangles), pH 8 (downward triangles), pH 10 (diamonds); (c) 100-nm silica particles in $0.5 \mathrm{M} \mathrm{NaCl}$ at pH 4 (squares), $\mathrm{pH} 7$ (circles), $\mathrm{pH} 10$ (upward triangles). Figure 7. (a) Mean particle size measured by DLS for $100-\mathrm{nm}$ silica particles at $\mathrm{pH} 7$ as a function of $\mathrm{NaCl}$ concentration. (b) Mean particle size measured by DLS for 100-nm silica particles as a function of $\mathrm{pH}$ in either $0.5 \mathrm{M} \mathrm{NaCl}$ (squares) or $0.1 \mathrm{M} \mathrm{K}_{3} \mathrm{PO}_{4}$ (circles). (c) Schematic describing agglomeration formation during experiment and breakup of agglomerates prior to AFM measurement. (d) Interaction energy versus separation distance calculated using DLVO model for various silica particle diameters in $0.5 \mathrm{M} \mathrm{NaCl}$ at pH 4: $100 \mathrm{~nm}$ (squares), $400 \mathrm{~nm}$ (circles), $800 \mathrm{~nm}$ (triangles).

Figure 8. Representative $5 \mu \mathrm{m} \times 5 \mu \mathrm{m}$ AFM scans from separate experiments showing deposition onto silica sensors from suspensions of $5.3 \mathrm{nM} 100-\mathrm{nm}$ silica particles in $0.6 \mathrm{M}$ $\mathrm{NaCl}$ (top row) at: (a) $\mathrm{pH} 4$, (b) pH 7, (c) pH 10, and in $0.1 \mathrm{M} \mathrm{K}_{3} \mathrm{PO}_{4}$ (bottom row) at: (d) pH 4, (e) $\mathrm{pH}$ 7, (f) $\mathrm{pH} 10$.

Figure 9. Normalized QCM frequency change responses (3 $3^{\text {rd }}$ harmonic) for adsorption of 5.3 nM 100-nm silica particles (open symbols) or $21.1 \mathrm{nM} 50-\mathrm{nm}$ silica particles (closed symbols) suspended in $0.5 \mathrm{M} \mathrm{NaCl}$ at pH 8 onto silica-coated QCM sensors: as-received (squares), roughened with 30T grit (triangles), or polished with ceria polishing slurry (diamonds). Dashed vertical lines denote times corresponding to the introduction of particle suspension and the re-introduction of $0.5 \mathrm{M} \mathrm{NaCl}$ background solution. 
Figure 10. Representative $5 \mu \mathrm{m}$ x $5 \mu \mathrm{m}$ AFM scans showing height maps of silica-coated QCM sensor surfaces. Columns, left to right: as-received, 30T grit-roughened, and ceriaslurry polished. Note that columns do not represent repeat scans of the same area. Sensor surfaces (a-c) before QCM adsorption experiments, (d-f) after adsorption of 21.1 nM 50-nm silica particles suspended in $0.5 \mathrm{M} \mathrm{NaCl}$ at $\mathrm{pH} \mathrm{8,} \mathrm{(g-i)} \mathrm{after} \mathrm{adsorption} \mathrm{of} 5.3 \mathrm{nM} 100-\mathrm{nm}$ silica particles suspended in $0.5 \mathrm{M} \mathrm{NaCl}$ at $\mathrm{pH}$ 8. Corresponding rms roughness is shown on each image. Color scale bar represents $-125 \mathrm{~nm}$ to $+125 \mathrm{~nm}$. (COLOR IN PRINT) 